\title{
Effect of Personal and Institutional Variables on Mathematics Achievement of Secondary School Students
}

\author{
Shivendra Pratap Singh*, Dr. Ali Imam** \\ *Research Scholar, Faculty of Education, Integral University, Lucknow (India) \\ **Associate Professor and HoD, Faculty of Education, Integral University, Lucknow (India)
}

\begin{abstract}
This study explored the effects of gender, attitude towards mathematics, socioeconomic status, use of computer, television watching, school type, school climate and medium of instructions on mathematics achievement. A convenience sample of 1944 students, 975 males and 969 female from thirty six schools of South-East Bihar (India) was used for study. The Mathematics Attitude Scale, Mathematics Achievement Test and School Climate Scale were used for data collection, while t-test, F-test followed by Duncan's Mean Test and correlation techniques were used for statistical analysis. The results revealed that there was a significant difference between mathematics achievement of boys and girls. The results of analysis showed that the males hold more positive attitude towards mathematics, school climate than female students. Moreover the students of central government schools and private managed schools had higher mathematics achievement in comparison to minority managed schools and state government schools. Further this study showed a positive correlation of attitude towards mathematics and school climate with mathematics achievement.
\end{abstract}

Key Words: Mathematics Achievement, Attitude towards Mathematics, Socioeconomic Status, School Climate

\section{Introduction:}

Education is described by Kirk and Gallagher (1983:34) as the mirror of the society, showing its strengths, weaknesses, hopes, biases and key values of its culture. Thus, education has a definite role to play in the development of people and countries. Education plays a significant role in the development of people because people are the wealth of any nation; therefore, people are viewed as a focus for development. It plays a vital role in the development of the country because education is the source of growth of any country. This may be one of the reasons why United Nations Educational Scientific and Cultural Organization (UNESCO) (2001:9) declare education a vehicle for and indicator of development.

Education and training play a vital role in assisting individuals and societies to adjust to social, economic and cultural changes and promote the development of the human capital essential for economic growth. Modern education, schooling in particular, aims at imparting knowledge, skills and attitudes required by the young ones to become functional in their respective societies. Schools are therefore intended to serve as agents for developing individual citizens within a country (Pandey 1996:77). In essence, schools are institutions where children are groomed to appreciate what the society in which they live stands for and are equipped in order for them to contribute to the advancement of their society.

Education is universally recognized as the most effective tool of bringing desirable change towards the social and economic betterment \& cultural transformation of a society in the status of human being and the country as a whole. It broadens the mental horizon of the human being. In one hand, education develops the total personality of the individual and on the other hand education contributes to the growth and development of society. It is only through education that the moral ideas, spiritual values, the aspiration of the nation and its cultural heritage are transformed from one generation to another for preservation, purification and sublimation into higher culture. Humphrys, Traxler and North (1960) have very correctly remarked "our future material and cultural welfare and progress, even our survival as a nation depends upon the wise use of abilities and energies of our people."

The nation that fails to make a genuine assessment of his human energy available in it is bound to lag behind others in the era of great competition in the national and international fields. An ideal system of education should enable individuals to know and develop to the fullest their physical and intellectual potentialities and promote their awareness of societal and human values so that they can develop a strong character and live better lives and function as responsible members of society.

Education is the key to all processes of development especially-human development. Catalytic action of education in this complex and dynamic growth process needs to be planned meticulously and executed with great sensibility.

Education is fundamental to all round development of human Potential -material and spiritual. It refines sensibility and perceptions that contribute to national cohesion, a scientific temperament and independence of 
mind and spirit. Thus furthering goal of socialism, secularism and democracy enshrined in our constitution. Educations develop manpower for different levels of economy and empower the poor masses to become selfreliant enough to participate in the process of national development. Education is thus an instrument for developing an economically prosperous society and for ensuring equity and social justice through enriching the knowledge.

An attempt to take a holistic view was made in 1986. The NPE-1986 is a landmark in the history of Indian education. The NPE-1986 visualized that education as a dynamic, cumulative, life long process providing diversity of learning opportunities to all segments of the society. It envisaged improvement and expansion of education in all sectors, elimination of disparities in access and stresses on improvement in the quality and relevance of education at all levels. The NPE -1986 also emphasized that education must play a positive and interventionist role in correcting social and regional imbalances in empowering women.

Subjects like science and mathematics have found a significant place in the curricula of primary and secondary school education. mathematics has become a substantial and integral part of an organized society. In today's world no one can live without mathematics for a single day.

Mathematics has played a decisive role in building up our civilization. But in doing so, it has also made itself essential for the existence and progress of modern world. In modern world we have to be more and more exact, we make larger use of quantitative terms. We have to be accurate to a split of second. All this requires large calculations and minute mathematical understanding.

Mathematical thinking is important for all members of a modern society as a habit of mind for its use in the work place, business and finance; and for personal decisions making. Mathematics is fundamental to national prosperity in providing tools for understanding science, engineering technology and economics. It is essential in public decision making and for participation in the knowledge economy.

Mathematics equips pupils with uniquely powerful ways to describe, analyze and change the world. It can stimulate moments of pleasure and wonder for all pupils when they solve a problem for the first time, discover a more elegant solution or notice hidden connections. Pupils who are functional in Mathematics and financially capable are able to think independently in applied and abstract ways and can reasons, solve problem and assess risk.

Mathematics is a creative discipline; the language of mathematics is international. The subject transcends cultural boundaries and its importance is universally recognized. Mathematics has developed over time as a means of solving problems and also for its own sake.

\section{Conceptual Frame Work}

Reviewing research prior to the 1970's, Maccoby and Jacklin (1974) concluded that gender difference favoring boys in mathematics ability and girls in verbal ability were well established.

By comparison, gender differences in achievement, especially mathematics, have not been consistent and continue to be a much debated topic (Leder, 1992). In an examination of 98 mathematics achievement studies, Frideman (1989) noted that until age 10 either no differences between genders or differences favoring girls are observed (e.g. Callahan \& Clements, 1984; Dossey et.al ., 1988, Hawn, Elliot, \& Des Jardines 1981). For the middle school years, some research favored girls (Tsai \& Walberg, 1983), and some favored boys (Hilton \& Berglund, 1974); other research showed no difference (Circicelli, 1967; Fennema \& Sherman, 1978). In her meta-analysis, Feridman (1989) observed that in five of seven studies 12th-grade boys out performed 12th-grade girls, with the remaining two studies showing no difference. Finally, with regards to standardized tests, boys tend to score higher than do girls (Halperen \& Lamay, 2000); the difference is more prevalent in the extremes of ability distribution (Willingham \& Cole, 1997). The research has consistently shown that at the end of high school boys perform better than girls on mathematics achievement tests whereas girls typically perform as well as boys in elementary school and perhaps, in middle school (Ewers \& Wood, 1992; Marsh, 1989; Skaalvik 1990). Also, there is some evidence that girls achieve better than boys on verbal tests (Halpern, 1992; Reuterberg, Emanuelsson \& Svensson, 1993).

The increasing gender differences in mathematics achievement in the high school years are most frequently explained in terms of sex stereotypes and differential sex role socialization patterns (e.g. Eccles, 1987; Fennema \& Peterson, 1985; Meece, Parsons, Kaczala, Goff \& Futterman 1982). When it is sex typed mathematics is viewed as a male domain (Eccles, Adler, Futterman, Goff, Kaczala, Meece \& Midgley, 1983; Fennema \& Sherman, 1978), Where as reading and language are stereotyped as female domains (Kaczala, 1981 Stein \& Smithells, 1969). Sex stereotypes also suggest that boys have better mathematics abilities than girls and that mathematics is more important for boys (Jacobs \& Eccles 1985). According to Jacobs \& Eccles sex stereotypes also suggest that girls have better verbal abilities than boys.

Affective background factors, such as attitudes and beliefs, play a central role in mathematics achievement (McLeod, 1992). the general relationship between attitude and achievement is based on the concept that the better the attitude a student has toward a subject or task, the higher the achievement or performance 
level tends to be. Ma (1997) observed that for trigonometry students, the attitudes that mathematics was important and enjoyable were significantly associated with achievement in mathematics. students who experienced more enjoyment while learning achieved higher scores.

Affective variables such as attitudes towards mathematics are related to the learning of mathematics and to the learning environment in classroom (Reyes, 1984). Current reforms efforts in mathematics education call for student to be active participants in the learning process and for solving no routine problems. While research has been pointed out that this type of environment support student construction of knowledge and organization of their thoughts (Wealthy \& Abshire, 2002) these changes may conflict with students attitudes towards mathematics. According to Mc Leod (1994), this type of reform should improve student interest and enjoyment of studying mathematics. therefore, to improve the learning of mathematics, it is important to study students' attitude towards mathematics (Fennema \& Sherman, 1976; Reyes, 1984).

Children begin to develop an attitude towards mathematics as soon as they are exposed to mathematics; these attitudes can have an effect on students learning in mathematics. For example, research has shown that some students are prohibited from learning mathematics to their full potential due to negative attitude towards mathematics (Reyes, 1980). Ma and Kishore (1997) conducted a meta-analysis of 113 studies that investigated the relationship between attitude towards mathematics and achievement in mathematics and found this relationship to both reliable and positive but not strong. While overall measures of attitude towards mathematics have only small positive relationship with achievement, a measure of a student's confidence with mathematics has relatively strong positive correlation with achievement in mathematics (e.g. Dowling, 1978). Research has shown that, when student are surer of themselves, teacher seem to pay more attention to them (Reyes, 1980).

Every research study deals with the solution of some problems of human interest. That is why the researcher has a definite purpose he has certain specific aims and goals to achieve through his research work. The present study was aimed at achieving the following objectives.

1- To compare the mathematics achievement of secondary school students on gender basis.

2- To study the relationship between attitude towards mathematics of secondary school students and mathematics achievements.

3- To study the impact of socio economic status of parents on mathematics achievement of secondary school students.

4- To study the impact of use of computer on achievement in mathematics of secondary school students.

5- To study the impact of television watching on achievement in mathematics of secondary school students.

6- To study the influence of school types on mathematics achievement of secondary school students.

7- To study the relationship of school climate with mathematics achievement of secondary school students.

8- To study the impact of medium of instructions on mathematics achievement of secondary school students.

Method: The current work is a descriptive study investigating if students' mathematics achievement differed significantly to a group of variables such as gender, attitude towards mathematics, socioeconomic status, use of computer, TV watching, school types, school climate and mathematics achievement. The sample consisted of 1944 secondary school students, selected from 36 schools of South-East Bihar (India) in which 975 (50.15\%) were male and 969 (49.85\%) were female students. In this study, schools are categorized on the basis of their management. For instance, Central Government Schools are fully controlled financed supported and administered by central government are English Medium coeducational schools, where pupils in IX and X are from all socio-economic strata and are admitted through all India based competitions. Private Managed Schools are prestigious English medium co-education schools managed by private societies having high reputations in society. That is the reason that pupils in these schools belong to well-to-do families with high socio-economic status (SES). State Government Schools are Hindi medium single sex schools run by State Government directly or indirectly through aids, and are widely known among general public for their poor management by Government machineries. The schools run by minority trusts through minority managements are termed as minority managed schools respectively. These schools can be seen as somewhere in between Christian missionaries and Muslim minority schools on one hand and Government and Government Aided schools on other hand.

\section{Attitude towards Mathematics}

\section{Tools Used:}

This attitude scale consists of 22 statements of likert type representing attitudes towards various aspects of mathematics such as enjoyment of mathematics, value of mathematics, mathematics anxiety, success in mathematics, mathematics as male domain, usefulness of mathematics, confidence to learn \& evaluation. The reliability of coefficient of the attitude scale is 0.90 as reported by the investigator and as calculated by split-half method. It is found to discriminate sufficiently between students of high attitude and those of low attitude. This scale appears to have high content validity and the method of selecting items supports this position. The range of 
scores on this tool extends from 22 to 110 with the mean of 66 . The summation of score earned by a student on all statements was taken as his attitude score. The total scores indicate favorableness or unfavourableness of the attitude of students towards mathematics. The higher is the score the more favourable is the attitude towards mathematics and lower is the score the more unfavourable is the attitude towards mathematics of the students.

\section{Mathematics Achievement Test}

The achievement test in mathematics for class IX students that is used in the present study was constructed by the investigator. This is a very comprehensive test based on 12 common chapters of class VIII mathematics text book (NCERT, New Delhi and Bihar State Education Board, Patna). The test consists of 70 items of multiple choice type representing achievement at various areas of mathematics such as 27 items in arithmetic, 21 items in algebra and 06 items in geometry, 12 items in menstruation and 4 item in statistics. The total score on the test as a whole was used as a measure of achievement in mathematics. All the items in the test were arranged in order of difficulty, the easy items being placed in the beginning and this was done to motivate the students. The difficulty values of items in the test between the range of 0.25 to 0.85 similarly, each item had a discriminating power greater than 0.30 . The test was based on the latest syllabus prescribed by the NCERT, New Delhi and Bihar State Education Board, Patna. This test had a fairly high content validity and its reliability is found to be 0.90 .

\section{A Personal and Familial Background Assessment Questionnaire}

The personal information sheet is prepared by the investigator. This sheet contains such questions requiring the subjects to give information on their parental occupational background as well as students' involvement in time spent in use of computer as well as time spent on watching T.V. etc.

\section{School Climate Scale}

This climate scale consists of 18 statements of Likert type representing various aspects of climate in school such as freedom, cooperation, motivation, enjoyment of schooling, discipline, health and hygiene, fee structure, equal opportunities, support of faculty and administration. The reliability of coefficient of the school climate scale is 0.89 as reported by the test developer. It is found to discriminate sufficiently between open and healthy climate of school and those of closed and worst climate. This scale appears to have content validity and the method of selecting items supports this position. The range of scores on this tool extends from 18 to 90 with the mean of 54. The summation of score earned by a student on all statements was taken as school climate score. The total scores indicate favorableness or unfavourableness of the climate of school. The higher is the score the more open and healthy climate in the school and lower is the score the more closed and worst climate in the school.

\section{Results and Analysis}

Data analysis is performed on computer with SPSS 17 software package. When data was analyzed to make a comparative study of the achievement in mathematics of male and female students (Table 1) the result shows a significant difference between achievement in mathematics of males and females ( $\mathrm{df}=1942, \mathrm{t}=2.40$ ).

Table 1: Comparison of mean mathematics achievement scores of male and female students

\begin{tabular}{|c|c|c|c|c|c|c|}
\hline Gender & N & $\begin{array}{c}\text { Mean } \\
\text { score }\end{array}$ & SD & t & df & $\begin{array}{c}\text { Sig./Not } \\
\text { sig. }\end{array}$ \\
\hline Male & 975 & 45.81 & 14.71 & \multirow{2}{*}{$2.40^{*}$} & 1942 & $\begin{array}{c}\text { Sig. at } \\
0.05 \\
\text { level }\end{array}$ \\
\hline Female & 969 & 44.19 & 15.13 & &
\end{tabular}

The total numbers of male and female students were $975 \& 969$ respectively as indicated by the table 1 . Out of 70 scores, the mean achievement scores in mathematics of male student is 45.81 and SD=14.71. In case of female students, the mean mathematics achievement score is 44.19 and $\mathrm{SD}=15.13$. The statistically calculated $\mathrm{t}$-value is 2.40 which is significant at 0.05 level with $1942 \mathrm{df}$. The result clearly indicates that there is significant difference between mean mathematics achievement score of male and female secondary school students. Both are not equally good but male students are better in mathematics achievement in comparison to female students. Thus the hypothesis stating that "Male and female students do not differ significantly on mathematics achievement" is rejected at 0.05 level of confidence. 
Table 2: Comparison of attitude towards mathematics, socioeconomic status and school climate scores of male and female students

\begin{tabular}{|c|c|c|c|c|c|}
\hline \multirow[t]{2}{*}{ Variables } & \multicolumn{2}{|c|}{$\begin{array}{c}\text { Male } \\
(\mathrm{N}=975)\end{array}$} & \multicolumn{2}{|c|}{$\begin{array}{c}\text { Female } \\
(\mathrm{N}=969)\end{array}$} & \multirow[t]{2}{*}{ t- value } \\
\hline & Mean & SD & Mean & SD & \\
\hline MAS $V_{1}$ & 78.79 & 15.84 & 74.12 & 16.67 & $6.33 * *$ \\
\hline SES $\quad V_{2}$ & 2.29 & 0.90 & 2.06 & 0.81 & $5.97 * *$ \\
\hline SCS $\quad V_{3}$ & 64.12 & 14.24 & 62.79 & 14.08 & $2.07 *$ \\
\hline
\end{tabular}

* Significant at 0.05 level, ** Significant at 0.01 level

Table 2 presents the result of comparison between male and female students on attitude towards mathematics, socio economic status and school climate. The means, standard deviations for both the groups along with corresponding t-value are given in the relevant columns of the table 2.

On attitude towards mathematics the mean scores of male students are 78.79 and standard deviation $(\mathrm{SD}=15.84)$ and the mean scores of female students are 74.12 and standard deviation $(\mathrm{SD}=16.67)$ and the $\mathrm{t}-$ value is 6.33 which is significant at 0.01 level. This shows that the male students have more favorable attitude towards mathematics than female students. Similarly, on socioeconomic status the mean scores of male students are 2.29 and standard deviation $(\mathrm{SD}=0.90)$ and the mean scores of female students are 2.06 and standard deviation $(\mathrm{SD}=0.81)$ and the $\mathrm{t}$-value is 5.97 which is significant at 0.01 level. This shows that the male students have more favorable socioeconomic status than female students. Similarly, on school climate the mean scores of male students are 64.12 and standard deviation $(\mathrm{SD}=14.24)$ and the mean scores of female students are 62.79 and standard deviation $(\mathrm{SD}=14.08)$ and the $\mathrm{t}$-value is 2.07 which is significant at 0.05 level. This shows that the male students have more favorable school climate than female students.

Table3 Relationship of attitude towards mathematics and mean mathematics achievement scores of secondary school students

\begin{tabular}{|l|l|r|r|l|}
\hline Variables & \multicolumn{1}{|c|}{ Mean } & SD & Correlation (r) \\
\hline ATM & 1944 & 76.46 & 16.42 & $0.2928^{* *}$ \\
\hline MAT & 1944 & 45.00 & 14.94 & \\
\hline
\end{tabular}

The analysis was employed to find out the relationship of attitude towards mathematics and achievement in mathematics. The total samples were 1944. The mean scores of attitude towards mathematics and achievement in mathematics of secondary school students were found to be 76.46 and 45.00 respectively. The correlation was applied for investigation, the mean scores, standard deviation (SD) and correlation coefficient ( $r$ ) values are given in table 3. The analysis does not confirm the prediction hypothesized in this study for the present sample. A strong relationship between attitude towards mathematics and achievement in mathematics has been demonstrated by this finding. Hence, the hypothesis stating that, "there is no significant relationship between attitude towards mathematics and achievement in mathematics of students" was rejected at 0.01 level of confidence.

Table 4 Comparison of mathematics achievement scores among the four categories of socio economic status $\left(E_{1}=\right.$ Very Poor, $E_{2}=$ Low, $E_{3}=$ Moderate, $E_{4}=$ High $)$ of secondary school students

\begin{tabular}{|c|c|c|c|c|c|c|c|c|c|}
\hline \multicolumn{2}{|c|}{$\begin{array}{l}\text { Very Poor } \\
\mathbf{E}_{1}(\mathbf{N}=355)\end{array}$} & \multicolumn{2}{|c|}{$\begin{array}{c}\text { Low } \\
\mathrm{E}_{2}(\mathrm{~N}=1118)\end{array}$} & \multicolumn{2}{|c|}{$\begin{array}{c}\text { Moderate } \\
\mathrm{E}_{3}(\mathrm{~N}=\mathbf{2 4 5})\end{array}$} & \multicolumn{2}{|c|}{$\begin{array}{c}\text { High } \\
\mathrm{E}_{4}(\mathrm{~N}=226) \\
\end{array}$} & \multirow[t]{2}{*}{$\begin{array}{l}\text { Sig. } \\
\text { pairs (*) }\end{array}$} & \multirow[t]{2}{*}{ F- value } \\
\hline Mean & SD & Mean & SD & Mean & SD & Mean & SD & & \\
\hline 39.35 & 16.36 & 44.18 & 14.51 & 47.34 & 12.53 & 55.42 & 11.07 & $\begin{array}{l}\mathrm{E}_{1} \mathrm{Vs}_{\mathrm{E}} \\
\mathrm{E}_{1} \mathrm{Vs} \mathrm{E}_{3} \\
\mathrm{E}_{1} \mathrm{Vs} \mathrm{E}_{4} \\
\mathrm{E}_{2} \mathrm{Vs} \mathrm{E}_{3} \\
\mathrm{E}_{2} \mathrm{Vs} \mathrm{E}_{4} \\
\mathrm{E}_{3} \mathrm{Vs} \mathrm{E}_{4}\end{array}$ & $62.02 * *$ \\
\hline
\end{tabular}

The analysis of variance was employed to find out the influence of socioeconomic status of students on mathematics achievement. The total sample was categorized into four group i.e. very poor, low, moderate and high socioeconomic status on the basis of annual income of their parents. The mean achievement scores of very 
poor, low, moderate and high socioeconomic status students were found to be $39.35,44.18,47.34$ and 55.42 respectively. Analysis of variance of the mathematics scores of the four group yielded $\mathrm{F}$ value as 62.02 which is significant at .01 level with df 3, 1940 (table 4). This implied that there is significant overall difference in the means of these groups. Hence F test was found significant therefore Duncan's post hoc test was applied for further investigations.

Further support to this conclusion, it is also provided by a test of significance of difference between the mean mathematics achievement scores of the four types of socioeconomic status as given in the table 4 .

The statistical method used in testing the major hypothesis was the Duncan's post hoc test for the difference between the means of four groups of socioeconomic status. The significant pairs obtained by comparing each group mean mathematics achievement score with that of every other groups show that out of six possible paired comparisons all six showed significant difference.

The result clearly shows that students of high socioeconomic status have highest mathematics achievement scores than the other three groups, then students of moderate socioeconomic status have higher mathematics achievement scores than low socioeconomic status students and very poor socioeconomic status students but lesser than the high socioeconomic status students. Low socioeconomic status students have higher mathematics score than very poor socioeconomic status students but lesser than high socioeconomic status students, moderate socioeconomic status students.

These analyses do not confirm the prediction hypothesized in this study for the present sample. A significant difference between mathematics achievement scores of student of different socioeconomic status has been demonstrated by the findings. Hence the hypothesis stating that "there is no significant difference among the categories of socio economic status and achievement in mathematics of students" was rejected.

Table 4 presents the result of comparison among four categories of socio economic status of students on attitude towards mathematics, participation in sports activities, NCC/NSS activities and school climate. The means, standard deviations for all the four groups along with corresponding F-value are given in the relevant columns of the table 4 .

The attitude towards mathematics scores of all the four categories of socioeconomic status were compared by using Analysis of Variance followed by Duncan's post hoc test. The results are shown in table 4 . Out of six possible paired comparisons, only four showed significant difference. Moderate socioeconomic status students had the highest attitude towards mathematics score than others. Then high socioeconomic status students had the higher attitude towards mathematics score than low and very poor socioeconomic status students after then low socio economic status students had the higher attitude towards mathematics score than very poor socioeconomic status students.

The overall result is that moderate socioeconomic status students had more favorable attitude towards mathematics than students of any other socioeconomic status.

Table 5 Comparison of mathematics achievement scores among the three categories of use of computer $\left(C_{1}=\right.$ Zero hour, $C_{2}=1-2$ hours, $C_{3}=$ More than 2 hours $)$ of secondary school students

\begin{tabular}{|l|l|l|l|l|l|l|l|}
\hline \multicolumn{2}{|c|}{$\begin{array}{c}\text { Zero Hour } \\
\mathbf{C}_{1} \text { (N=1491) }\end{array}$} & \multicolumn{2}{c|}{$\begin{array}{c}\text { 1-2 Hours } \\
\mathbf{C}_{2} \text { (N=396) }\end{array}$} & \multicolumn{2}{|c|}{$\begin{array}{c}\text { More than 2 } \\
\text { Hours } \\
\mathbf{C}_{\mathbf{3}} \text { (N=57) }\end{array}$} & \multirow{2}{*}{$\begin{array}{l}\text { Significant } \\
\text { pairs (*) }\end{array}$} & F- value \\
\hline Mean & SD & Mean & SD & Mean & SD & & \\
\hline 44.09 & 15.23 & 48.11 & 13.74 & 47.23 & 11.98 & $\mathrm{C}_{1} \mathrm{Vs}_{2}$ & $12.09 * *$ \\
\hline
\end{tabular}

The analysis of variance was employed to find out the influence of regular use of computer of students on mathematics achievement. The total sample was categorized into three groups according to their usages i.e. zero hours, 1-2 hours and more than 2 hours. The mean achievement scores of zero hours, 1-2 hours and more than 2 hours of students were found to be 44.09, 48.11and 47.23 respectively. Analysis of variance of the mathematics scores of the three groups yielded $\mathrm{F}$ value as 8.11 which is significant at .01 level with $\mathrm{df} 2,1941$ (table 5). This implied that there is significant overall difference in the means of these groups. Hence F test was found significant therefore Duncan's post hoc test was applied for further investigations.

Further support to this conclusion, it is also provided by a test of significance of difference between the mean mathematics achievement scores of the three groups according to their usages of computer as given in the table 5.

The statistical method used in testing the major hypothesis was the Duncan's post hoc test for the difference between the means of three groups. The significant pairs obtained by comparing each group mean mathematics achievement score with that of every other group shows that out of three possible paired comparisons only one showed significant difference. 
It is clear from the table 5 that there is only significant difference between group of zero hours and 1-2 hour group and rest of all two pairs are not significant.

The result clearly shows that students of 1-2 hours group have highest mathematics achievement scores but more than 2 hour group have higher mathematics achievement scores than zero hour group.

These analyses partially confirm and partially reject the prediction hypothesized in this study for the present sample. A partial relationship between mathematics achievement scores of student and use of computer has been demonstrated by the findings. Hence the hypothesis stating that "there is no significant difference among the categories of use of computer and mathematics achievement of students" was partially accepted and partially rejected.

Table 6 Comparison of mathematics achievement scores among the four categories of $\mathrm{TV}$ watching $\left(\mathrm{T}_{1}=\right.$ Zero hours, $T_{2}=$ Less than 1 hour, $T_{3}=\mathbf{1 - 2}$ hours, $E_{4}=$ More than 2 hours) of secondary school students -Duncan's Mean test

\begin{tabular}{|c|c|c|c|c|c|c|c|c|c|}
\hline \multicolumn{2}{|c|}{$\begin{array}{l}\text { Zero Hour } \\
T_{1}(N=482)\end{array}$} & \multicolumn{2}{|c|}{$\begin{array}{c}\text { Less than } 1 \text { Hour } \\
T_{2}(N=894)\end{array}$} & \multicolumn{2}{|c|}{$\begin{array}{l}\text { 1-2 Hours } \\
T_{3}(N=449)\end{array}$} & \multicolumn{2}{|c|}{$\begin{array}{c}\text { More than } 2 \\
\text { Hours } \\
T_{4}(\mathrm{~N}=119)\end{array}$} & \multirow[t]{2}{*}{$\begin{array}{l}\text { Significant } \\
\text { pairs }(*)\end{array}$} & \multirow[t]{2}{*}{ F- value } \\
\hline Mean & SD & Mean & SD & Mean & SD & Mean & SD & & \\
\hline 43.57 & 15.25 & 45.80 & 15.39 & 44.90 & 13.98 & 45.18 & 13.41 & $\mathrm{~T}_{1} \mathrm{Vs} \mathrm{T}_{2}$ & $2.34^{*}$ \\
\hline
\end{tabular}

The analysis of variance was employed to find out the influence of time spent on T.V. watching of students on mathematics achievement. The total sample was categorized into four groups i.e. zero hours, less than 1 hour, 1 to 2 hours and more than 2 hours on the basis of time spent on T.V. watching. The mean achievement scores of zero hours, less than 1 hour, 1 to 2 hours and more than 2 hours students were found to be 43.57, 45.80, 44.90 and 45.18 respectively. Analysis of variance of the mathematics scores of the four group yielded $\mathrm{F}$ value as 2.34 which is significant at .05 level with df 3, 1940 (table 6). This implied that there is significant overall difference in the means of these groups. Hence $\mathrm{F}$ test was found significant therefore Duncan's post hoc test was applied for further investigations.

Further support to this conclusion, it is also provided by a test of significance of difference between the mean mathematics achievement scores of the four types of T.V. watching as given in the table 6 .

The statistical method used in testing the major hypothesis was the Duncan's post hoc test for the difference between the means of four groups of T.V. watching. The significant pairs obtained by comparing each group mean mathematics achievement score with that of every other groups show that out of six possible paired comparisons only one showed significant difference.

The result clearly shows that students of less than 1 hour group have highest mathematics achievement scores than the other three groups, then students of more than 2 hours group have higher mathematics achievement scores than 1 to 2 hours group students and zero hours group students but lesser than the 1 to 2 hours group students. 1 to 2 hours group students have higher mathematics score than zero hours group students but lesser than less than 1 hour, more than 2 hours group students.

These analyses do not confirm the prediction hypothesized in this study for the present sample. A significant difference between mathematics achievement scores of student of different T.V. watching group has been demonstrated by the findings. Hence the hypothesis stating that "there is no significant difference among the categories of amount of time spent on television watching and mathematics achievement of students" was rejected.

Table 7 Comparison of mathematics achievement scores among the four categories of schools $\left(\mathbf{S}_{1}=\right.$ Central Government Schools, $S_{2}=$ State Government Schools, $S_{3}=$ Minority Management Schools, $S_{4}=$ Private Management Schools) of secondary school students

$$
\text { -Duncan's Mean test }
$$

\begin{tabular}{|c|c|c|c|c|c|c|c|c|c|}
\hline \multicolumn{2}{|c|}{$\begin{array}{l}\text { Central Govt. } \\
S_{1}(N=444)\end{array}$} & \multicolumn{2}{|c|}{$\begin{array}{r}\text { State } \\
\text { Govt. } \\
S_{2}(\mathrm{~N}=500)\end{array}$} & \multicolumn{2}{|c|}{$\begin{array}{l}\text { Minority } \\
\text { Managed } \\
\mathbf{S}_{3}(\mathbf{N}=500)\end{array}$} & \multicolumn{2}{|c|}{$\begin{array}{l}\text { Private } \\
\text { Managed } \\
S_{4}(N=500)\end{array}$} & \multirow[t]{2}{*}{$\begin{array}{l}\text { Significant } \\
\text { pairs }(*)\end{array}$} & \multirow[t]{2}{*}{ F- value } \\
\hline Mean & SD & Mean & SD & Mean & SD & Mean & SD & & \\
\hline 52.37 & 10.46 & 30.92 & 12.46 & 48.44 & 9.71 & 49.10 & 15.70 & $\begin{array}{l}S_{1} V_{s} S_{2} \\
S_{1} V_{s} S_{3} \\
S_{1} V_{s} S_{4} \\
S_{2} V_{s} S_{3} \\
S_{2} V_{s} S_{4}\end{array}$ & $300.49 * *$ \\
\hline
\end{tabular}

** Significant at 0.01 level 
To find out the influence of school types on mathematics achievement of the students, the total sample was categorized into four groups on the basis of the management of the schools i.e. Central Government Schools, State Government Schools, Minority Managed Schools and Private Managed Schools. Analysis of variance was employed to determine the significance of difference in mathematics achievement scores of the students of the said four groups of schools. The calculated value of $\mathrm{F}$ is 300.49 ; which is significant at df 3 , 1940. The result shows that there were overall significant difference between the means hence Duncan's post hoc test was applied for further investigation.

Further support to this conclusion, it is also provided by a test of significance of difference between the mean mathematics achievement scores of the four types of schools as given in the table 7 .

The statistical method used in testing the major hypothesis was the Duncan's post hoc test for the difference between the means of four groups. The significant pairs obtained by comparing each group mean mathematics achievement score with that of every other group shows that out of six possible paired comparisons only five showed significant difference.

Further the table 7 shows that out of all six pairs of group's five pairs of groups are significant except the pair between minority and private school students, which is not significant.

The result clearly shows that students of central government school have highest mathematics achievement scores than the other three groups, then students of private managed school have higher mathematics achievement scores than state government school and minority managed schools students but lesser than the central government school students. Minority students have higher mathematics score than state government school but lesser than central government school, private managed school students.

These analyses do not confirm the prediction hypothesized in this study for the present sample. A relationship between mathematics achievement scores of student and type of schools has been demonstrated by the findings. Hence the hypothesis stating that "there is no significant difference among the categories of type of schools and mathematics achievement of students" was rejected.

Table 8 Relationship of school climate and mean mathematics achievement scores of secondary school students

\begin{tabular}{|c|c|c|c|c|}
\hline Variables & $\mathbf{N}$ & Mean & SD & $\begin{array}{c}\text { Correlation } \\
\text { Coefficient (r) }\end{array}$ \\
\cline { 1 - 4 } MAT & 1944 & 45.00 & 14.94 & $0.2135^{* *}$ \\
\hline SCS & 1944 & 39.63 .46 & 14.17 & ** Significant at 0.01 level \\
\cline { 1 - 2 }
\end{tabular}

The analysis was employed to find out the relationship of school climate and achievement in mathematics. The total samples were 1944. The mean scores and standard deviations of achievement in mathematics and school climate of secondary school students were found to be $45.00 \& \mathrm{SD}=14.94$ and $63.46 \&$ $\mathrm{SD}=14.17$ respectively. The correlation was applied for investigation, the mean scores, standard deviations and correlation coefficient ( $\mathrm{r}$ ) values are given in table 8 . The analysis does not confirm the prediction hypothesized in this study for the present sample. A strong relationship between school climate and achievement in mathematics has been demonstrated by this finding. Hence, the hypothesis stating that, "there is no significant relationship between school climate and mathematics achievement of secondary school students" was rejected at 0.01 level.

Table 9 Comparison of mathematics achievement scores of students on the basis of their medium of instruction

\begin{tabular}{|c|c|c|c|c|c|c|}
\hline $\begin{array}{c}\text { Medium of } \\
\text { instruction }\end{array}$ & $\begin{array}{c}\text { No. of } \\
\text { students N }\end{array}$ & Mean & SD & df & t-value & Sig. \\
\hline English & 1282 & 48.90 & 12.99 & 1942 & $17.16^{* *}$ & 0.01 level \\
\hline Hindi & 662 & 37.46 & 15.58 & &
\end{tabular}

**Significant at 0.01 level

The total numbers of English medium and Hindi medium students were 1282 \& 662 respectively as indicated by the table 9. Out of 70 scores, the mean achievement scores in mathematics of English medium student is 48.90 and standard deviation $(\mathrm{SD}=12.99)$ in case of Hindi medium students, the mean mathematics achievement score is 37.46 and standard deviation $(\mathrm{SD}=15.58)$. The statistically calculated t-value is 17.16; which is significant at 0.01 level with $1942 \mathrm{df}$. The result clearly indicates that there is significant difference between mean mathematics achievement score of English medium and Hindi medium secondary school 
students. Both are not equally good and they differ in their mathematics achievement. Thus the thirteenth hypothesis stating that, "there is no significant difference between medium of instruction and mathematics achievement of secondary school students" is rejected at 0.01 level.

\section{Discussion}

The purpose of the present research was to determine the effects of personal and institutional factors on achievement in mathematics. These two variables were chosen for analysis because they are manipulable variables that have been identified as important influences on achievement in previous research. Data from a large contemporary sample of high schools students were analyzed. F-test followed by Duncan's Mean test, ttest and correlation techniques were used to determine the effects of these variables on academic achievement, while controlling for other relevant background influences.

The results of the analysis of data shows that the personal factors indices, gender, attitude towards mathematics, socioeconomic status, use of computer, T.V. watching and institutional factors indices, type of schools, school climate, medium of instruction all had significant effect on mathematics achievement scores in expected direction.

There was significant difference in mathematics achievement scores between boys and girls in the present study. The finding of this study is supported by Asante, K Oppong (2010), Forgasz, Helen (2010) found that generally female students attained higher grades in all other school subjects besides mathematics, science and IT than their male counterparts. Gender differences and the findings on gender differences in mathematics achievement are not newly emerged fact. long research history in this area has demonstrated that male advantage in mathematics achievement is a universal phenomenon (Beaton et al, 1996; Mullis et.al., 2000). Researchers have shown that boys tend to score higher than girls on problems that include spatial representation, measurement, proportions as well as complex problems; whereas girls tend to score higher on computations, simple problems and graph reading (Beaton et.al. 1999) According to some research findings, the gender gap in mathematics achievement increases during middle school and becomes more disturbing at the upper secondary level (Fennema et.al. 1998; Fennema, 1985). Friedman (1989) noted that until age 10 either no differences between genders or favoring girls are observed. He observed that 12th grade boys out performed girls, finally, other studies (Fox, Brody \& Tobin, 1980) emphasized high mathematics achievement being dominated by males. Deder (1992) has also reported the existence of gender differences in science subject in general as well as in mathematics but Branholt, Goodraw \& Conney (1999), Ewers \& Wood 1992; Skaalvik, 1990; Hilton \& Berglund (1974). Awartani and Gray (1989) reported no significant differences between male and female students in mathematics achievement. Ma (1995) studied a sample of high school seniors, based on algebra and geometry achievement. He found no gender differences in algebra but males significantly outperformed females in geometry. Gender differences in achievement, especially mathematics, have not been consistent and continue to be a much debated topic (Leder, 1992).

It is generally believed that student attitude towards a subject determines their success in that subject. In other words, favourable attitude result to good achievement in a subject. A student's constant failure in a school subject and mathematics in particular can make him to believe that he can never do well on the subject thus accepting defeat. On the other hand, his successful experience can make him to develop a positive attitude towards learning the subject. This suggests that student's attitude towards mathematics could be enhanced through effective teaching strategies. It has in fact been confirmed that effective teaching strategies can create positive attitude on the students towards school subjects (Bekee, 1987; Belogun and Olarewaju, 1992; Akinsola 1994; Akale 1997, Alowojaiye 2000, Tngtf, Nellai (2010), Tzuriel, David (2010), Khatoon, Tahira; Mahmood, Sadia (2011), Yenilmez, KÄursat; Girginer, Nuray and Uzun, ÄOzlem (2011), Olatunde, Yara P. (2011)).

It becomes quite clear that attitude towards mathematics and achievement in it are positively related in this study, the higher the attitude of students towards mathematics, higher the achievement in mathematics of the students. Other studies lend support to this relationship. Ma (1997), observed that for trigonometry students, the attitudes that mathematics was important and enjoyable were significantly associated with achievement in mathematics. Jha (1992), Kumar (1980), Rech (1996) concluded that there is a positive and significant correlation between proper attitude towards mathematics and achievement in it. The relationship between attitude towards mathematics and ability in the subject has been found to be interactive and dynamic (Reyes, 1984). Increasing the level of mathematics achievement may, in and of itself, actually result in more positive attitude. Pal (1989) observed that better attitude towards mathematics ensures better achievement of the students in mathematics at secondary level. Jayaraman (1989) found a significant relation between attitude towards learning mathematics and achievement in mathematics. Enemark and wise (1981) demonstrated that the attitudinal variables are significant indicators of mathematics achievement. Steenkamp (1982) concluded that primary among the variables that determine AIM is ATM. These conclusions represent the view of a strong relationship between ATM and AIM, with correlations above 0.40 as supported by a number of researches (Khoosterman, 1991; Minato, 1983; Minato \& Yanasre, 1984; Randhawa \& Beamer, 1992). on the other hand, 
the research literature, however, has failed to provide consistent findings the relationship between attitude towards mathematics and achievement in it. A number of researchers have demonstrated that the ATM-AIM correlation is quite low, ranging prom zero to 0.25 in absolute value and they have concluded that the ATMAIM relationship is weak and cannot be considered to be of practical significance (Abrego, 1966; Deighan 1971; Vachon, 1984; Walf \& Blixt, 1981). Robinson (1975) Concluded that ATM accounts for, at best, $15 \%$ of the variance in AIM, indicating that the relationship has no useful implications for educational practice. Thus, academic achievement in mathematics is functionality dependent on attitude of the students towards learning mathematics. It indicates that students with favourable attitude towards mathematics may perform better in achievement test in mathematics as compared to the students with unfavourable attitude. In the light of the above discussion it is evident that attitude of the learners are the important correlates of their academic achievement.

The results presented support the idea that regular use of computer brings some benefits for students. The result shows that use of computer brings some benefits for students. The result shows that use of computer for $1 \mathrm{hr}$ to $2 \mathrm{hrs}$ per day have increasingly positive effects on achievement of students. The student have no use of computer and also students who have using computer more the $2 \mathrm{hrs}$ per day have increasingly negative effects on achievement. Our results suggest that more time and no time spent on use of computer have negative effects on the mathematics achievement of high schools students. In general the academic performance of both, the more use of computer students and no use of computer students was found worse. Hence amount of time spent on using computer is the important criteria for performance of the students. This study is supported by QING Li; Xin, Ma (2010) A meta-analysis of 85 independent effect sizes extracted from 46 primary studies involving a total of 36,793 learners indicated statistically significant positive effects of CT on mathematics achievement.

The results presented support the idea that T.V. watching brings some benefits for students. The result shows that watching brings some benefits for students. The result shows that watching T.V. for less than 1 $\mathrm{hr}$ to $2 \mathrm{hrs}$ per day has increasingly positive effects on achievement of students. The student have no TV in their homes and not watching TV and also students who have TV in their homes and viewing more the $2 \mathrm{hrs}$ per day have increasingly negative effects on achievement. Our results suggest that more time and no time spent watching TV has negative effects on the mathematics achievement of high schools students. In general the academic performance of both, the more TV students and no TV students was found worse. Hence amount of time spent on viewing TV is the important criteria for performance of the students. This study is supported by williams et al (1982) who have seen a positive effect for up to $10 \mathrm{hr}$ of viewing TV per week and with more viewing having increasingly negative effects on achievement. Using a national sample from the high school and beyond longitudinal survey, Kith, et al (1986) found a small negative relationship between achievement and amount of TV watching. However, the negative effect of TV watching is not found consistently (Gortmker, Salter, Walker \& Dietz, 1990); suggesting the relationship may be weak and therefore sensitive to methodological variations. Indeed, Comstock (1991) concluded that the evidence indicates a modest causal contribution by television to lesser achievement. The findings of this study, along with findings of other researches (Lemish \& Rice, 1986) suggest that students benefit from TV viewing. Nevertheless, even for young children, viewing should be probably be limited to the existing estimates of optional viewing time such as up to $2 \mathrm{hrs}$ a day. Television viewing has traditionally been assumed to lesser achievement (Comstock, 1991, Keith, Reimers, Fehrman, Pottebaum \& Aubey, 1986). Simply, television viewing displaces academic activities and reduces the amount of time available for completing homework and other academic activities, thereby reducing achievement. Cooper et al (1999) observed a significant negative association between achievement and television viewing (mean viewing was $1-2 \mathrm{hr}$ per night).

Now coming to different types of schools, another important variable of the study a definite relationship has been found to exist between this variable and mathematics achievement of the students. Different type of schools, managed by different authority has different types of influences on performance of their students. In this way sample schools range from good to poor in their performance. For instance Central government schools are running on the lines of public schools and have very high reputations. In this study student of Central government schools have got highest score than the students of other types of schools. The students of private managed schools also achieved significantly higher achievement mathematics score than students of other types of schools but lesser than Central government schools, students of minority managed schools achieved significantly higher mathematics score than the students of the state government Schools. In this way students of central government schools are high achiever and students of state government schools are low achiever in mathematics. It is clear from the present study that in India Central government schools are managed by Government of India and high status English medium schools where high intellectual background students are able to study. This is the reason that students of Central government schools were found to be academically competent than those of all the students of other types of schools. Goldhabar (1996) found that private schools have no statistically significant advantage in the education on mathematics and reading over 
public schools. Similarly a study conducted by white (1992) found that the difference in achievement in private and public schools is trivial in size and highly uncertain. The reasons of the variations in the results of the students conducted in west and India may be because in the developed world both private and public schools operate with similar basic facilities available with them which are not true in case of India. The variations in the academic achievement of students in developed world is due to family background while as in developing world including India, school factors are largely responsible for variations in achievement levels of students. Heyneman and Loxely (1983), it was concluded that the factors determining learners achievement in developed world are different from that in developing world. it was found that home environment factors are more important and reliable factors in predicting learner's achievement in the developed world where as school factors continue to be important in predicting learner's achievement in the developing world.

\section{Delimitations:}

It is not possible in a single research study to cover every aspect of variables associated with the problem under investigation. Although, the problem is very natural and is prevalent everywhere yet due to shortage of time and resources all the aspects variables could not be covered and the study is limited in several ways. It had to be determined in terms of population covered, sample selected, scope of variables studied and the scope of genralizability of finding and so on.

1. Due to the shortage of time and resources the study was carried out only on students of class $9^{\text {th }}$ although problem of achievement is common to elementary classes yet the focus of the study has been on the secondary stage only.

2. The phenomenon of achievement has been studied on in relation to selected personal and institutional variables only.

3. The scope of study covers only a few districts of South-East Bihar (India) as the investigator felt that no study had been conducted in this area. Hence the generalizability of the findings would be limited accordingly.

4. The tool for the assessment of the achievement in mathematics is developed by investigator himself. Although attempt has been made for proper item selection, try out, estimation of reliability and validity of the tool, detailed norms still remain to be prepared.

5. The tool for the assessment of the climate in school is developed by investigator himself. Although attempt has been made for proper item selection, try out, estimation of reliability and validity of the tool, detailed norms still remain to be prepared.

6. It is desirable that the researcher reaches first hand or original sources for the study, but as access to some material was not possible materials taken from available secondary sources has been used.

7. Though the stratified random sampling is adapted for selection of samples at which extent it was practicable but due to some other factors like permission for administration of the tests and availability of schools made the researcher forced to adopt the purposive sampling as an alternative measure for the study.

\section{References}

[1]. Anick, C.M.; Carpenter, T.P., \& smith (1981). Minorities and mathematics: Results from the national assessment of educational press. Mathematics Teacher, 74, 560-566.

[2]. Awartani, M., \& Gray, M.W. (1989). Cultural influences on sex differentials in mathematics aptitude and achievement. International Journal of Mathematical Journal in science and Technology, 20(2), 317-320.

[3]. Callahan, L.G., \& Clements, D.H. (1984). Sex differences in rote counting ability on entry to first grade: some observations. Journal for Research in Mathematics Education, 15, 378-382.

[4]. Comstock, G. (1991). Television and the American child. New York: Academic Press.

[5]. Ewers, C.A. \& Wood, N.L. (1992). Sex and ability differences in children's mathematics self-efficacy and prediction accuracy. Paper presented at the annual meeting of the American Educational Research Association in San Francisco, April.

[6]. Fennema, E., (1989). The study of affect and mathematics: A proposed generic model for research. In D.B. Mc Leod \& V.M. Adams (Eds.), Affect and mathematical problem solving: A new perspective (pp. 205-219). New York: Springer-Verlag.

[7]. Friedman, L. (1989). Mathematics and the gender gap : A meta analysis of recent studies on sex differences in mathematics tasks. Review of Educational Research, 59(2), 185-213.

[8]. Gortmaker, S.L Salter C.A. walker D.K. \& Diets. W.H. (1990) the impact of television viewing on mental aptitude and achievement: A longitudinal study Public opinion Quarterly, 54 594-604.

[9]. Haller, E.J. (1992). High school size and student indiscipline: Another aspect of the school consolidation issue? Educational Evaluation and Policy Analysis, 14(2) 145-156.

[10]. Jacobs, J. E. \& Eccles, E. (1985). Gender differences in mathematics ability: the impact of media reports on parents. Educational Researcher, 14, 21-25.

[11]. Leder, G.C. (1992). Mathematics and gender: Changing perspectives. In D.A. Grows (Ed.) Handbook of research on mathematics teaching and learning pp. 597-622) New York, Macmillan.

[12]. McLeod. D.B. (1992). Research affect in mathematics education: 4 reconceptualization In D.A. Grouws (Ed) Hand book of research on mathematics leading and learning pp.-575-596, New York, Macmillan.

[13]. Ma, X (1995). Gender differences in mathematics achievement between Canadian and Asian education systems. The Journal of Educational Research, 89, 118-127. 
[14]. Ma, X. (1997). Reciprocal relationship between attitude towards mathematics and achievement in mathematics. The Journal of Educational Research, 90(4), 221-229.

[15]. Mullis IVS martin M.O. Beton A.E. Gonzalez E.J. Kelly D.L. \& Smith T.A. (1998) Mathematics and science achievement in the final year of secondary school. IEAS third international mathematics and Science study (TIMSS) chestnut Hill, MA Boston College.

[16]. Reyes, L.H. (1984). Affective variables and mathematics education, Elementary school Journal 84, 558-581.

[17]. Shukla Chandra Shekher (1982) Achievement of Primary School Children in Relation to their Socio Economic Status and Family size, Ph.D. Thesis Faculty of Education, Banaras Hindu University.

[18]. Williams, P.A. Haertel, E.H., Haertel, G.D., \& Walberg, H.J. (1982). The impact of leisure-time television on school learning. American Educational Research Journal, 19(1), 19-50.

[19]. Wilkins, J.L.M., \& MA, X (2002). Predicting students' growth in Mathematical content knowledge. Journal of Educational Research 95(5), 288-298. 